\title{
Rheumatoid arthritis patients receive less frequent acute reperfusion and secondary prevention therapy after myocardial infarction compared with the general population
}

\author{
Sharon Van Doornum ${ }^{1,2^{*}}$, Caroline Brand ${ }^{3,4}$, Vijaya Sundararajan ${ }^{5}$, Andrew E Ajani ${ }^{1,6,7}$, Ian P Wicks ${ }^{1,2}$
}

\begin{abstract}
Introduction: The 30-day case-fatality rate after acute myocardial infarction (MI) for rheumatoid arthritis (RA) patients is twice that of the general population. This study compared the frequency and timeliness of early reperfusion therapy and treatment with secondary prevention medications after acute MI in RA patients and controls.
\end{abstract}

Methods: We performed a structured medical chart review of RA patients and matched controls who had been admitted with acute Ml to one of three hospitals in Victoria, Australia, between 1995 and 2005. The administration and timing of acute reperfusion therapy and in-hospital treatment with secondary prevention medications were compared between the two groups. Acute reperfusion was defined as thrombolysis or percutaneous coronary intervention (PCl) within 12 hours of the first symptom of Ml.

Results: The medical charts of 90 RA patients and 90 matched controls were reviewed. The RA patients were significantly less likely to receive acute reperfusion compared with the controls (16\% versus $37 \%$ : odds ratio (OR), 0.27 ; $95 \%$ confidence interval (Cl), 0.10 to 0.64$)$ ), and this difference persisted after adjusting for type of $\mathrm{Ml}$, clinical setting of $\mathrm{Ml}$, and prior $\mathrm{Ml}(\mathrm{OR}, 0.2 ; 95 \% \mathrm{Cl}, 0.05$ to 0.6$)$. The RA patients also received less-frequent in-hospital treatment with beta blockers ( $71 \%$ versus $83 \%$; $\mathrm{OR}, 0.42 ; 95 \% \mathrm{Cl}, 0.18$ to 0.96 ) and lipid-lowering agents (40\% versus 70\%; OR, 0.21; $95 \% \mathrm{Cl}, 0.09$ to 0.46$)$.

Conclusions: RA patients who experience acute $\mathrm{MI}$ receive acute reperfusion and secondary prevention medications less frequently than do controls. This may contribute to higher case-fatality rates after MI in RA patients.

\section{Introduction}

Rheumatoid arthritis (RA) is a chronic, systemic inflammatory disease that manifests primarily as inflammation in synovial joints. It is now widely recognized that RA patients also experience excess cardiovascular morbidity and mortality compared with the general population [1]. Not only do RA patients have an increased incidence of cardiovascular events, such as acute myocardial infarction (MI) [2-7], but they also have an increased case-

\footnotetext{
* Correspondence: svd@unimelb.edu.au

'Department of Medicine (RMH/WH), The University of Melbourne, Grattan

Street, Parkville, 3050, Australia

Full list of author information is available at the end of the article
}

fatality rate after acute MI compared with the general population [8-10]. For example, in our previous study of almost 30,000 individuals who had experienced a first acute MI, the adjusted odds ratio (OR) for 30-day mortality in RA patients versus controls was 1.9 (95\% confidence interval (CI), 1.3 to 2.7 ) [8].

The reasons for a higher case-fatality rate after $\mathrm{MI}$ in RA patients are not known. Possible explanations include delays in seeking medical attention or in diagnosis, detrimental effects of systemic inflammation or concurrent RA medications or both, different patterns of coronary artery disease in RA patients, or differential treatment after the acute cardiac event. In our

\section{Ciomed Central}


aforementioned study, we found that percutaneous coronary intervention (PCI) was performed half as often in RA patients as in the controls (adjusted OR, 0.5; 95\% $\mathrm{CI}, 0.3$ to 0.8 ), which suggests that RA patients receive differential treatment [8]. However, in that study, we had no data on the frequency of administration of thrombolysis, the reason(s) that PCI was less frequently used in the RA patients, nor the frequency of treatment with secondary prevention pharmacotherapy after MI.

The aim of the present study was to investigate whether the treatment received by RA patients after an acute MI is different from that received by the general population, and if so, why. We addressed this by comparing the frequency of acute reperfusion therapy (PCI or thrombolysis) and treatment with secondary prevention pharmacotherapy in RA patients compared with controls after acute MI.

\section{Materials and methods}

We performed a structured medical chart review of RA patients and matched controls who had been admitted with acute MI to one of three hospitals in Victoria, Australia (The Royal Melbourne Hospital, The Alfred Hospital, and Epworth Hospital) between 1995 and 2005. The Royal Melbourne and Alfred hospitals are major metropolitan public hospitals, and the Epworth is a major metropolitan private hospital. The study was approved by the ethics committee of each of the participating hospitals. Informed consent from patients was not required by the ethics committees, as the study involved chart review only.

\section{Identification of study population}

We obtained from each hospital a de-identified list of all patients with a discharge diagnosis of acute MI (International Classification of Diseases (ICD) 9-CM (Aust v2) code 410.xx or ICD 10-AM code I21.xx) between 1 July 1995 and 30 June 2005 (hereafter referred to as "MI admission"). The 15,278 individuals had received a discharge diagnosis of acute MI from one of the three participating hospitals between 1 July 1995 and 30 June 2005. We identified RA patients as those who had also received a discharge diagnosis code for RA (ICD 9-CM (Aust v2) code 714.xx or ICD 10-AM codes M05.xx, M06.xx, or M08.0) during the MI admission or any previous admission. Within the cohort of 15,278 acute MI cases, 133 individuals had also received a discharge diagnosis of RA and were classified as RA cases. The remaining 15,145 patients were classified as non-RA. The medical charts of the 133 RA patients were requested for formal review. Forty-three (32\%) of the RA cases were not able to be included in the study: nine (7\%) of the charts were unavailable or incomplete, 20 (16\%) did not meet criteria for RA, and 14 (11\%) did not meet criteria for definite MI. The remaining $90 \mathrm{RA}$ patients (50, Alfred Hospital; 25, Royal Melbourne Hospital; 15, Epworth Hospital) were included in the study. The chart review of the control patients was performed in a similar manner. Thirty-four (38\%) of the 90 matched controls initially selected were not able to be included in the study: 18 (20\%) charts were unavailable or incomplete, and 16 (18\%) patients did not meet criteria for definite MI. In these instances, a second matched control was selected from the de-identified list.

\section{Definitions used for the chart review}

The diagnosis of RA was considered to be correct if a doctor had documented the diagnosis of RA in the chart during the MI admission or during any previous hospital encounter. We chose this definition of RA because comprehensive documentation of RA diagnostic criteria is frequently omitted in hospital medical notes, especially if the patient has been admitted with a nonrheumatologic medical condition (such as $\mathrm{MI}$ ). We predicted that the use of more-stringent diagnostic criteria would result in the exclusion of many patients who truly had RA, because of an absence of detailed medical notes, rather than any doubt about the diagnosis. For each patient who met our definition of RA, we recorded additional information supporting the diagnosis of RA, including whether the patient fulfilled American College of Rheumatology (ACR) diagnostic criteria [11] or was being treated with disease-modifying antirheumatic drug (DMARD) therapy or both.

Myocardial infarction was defined according to the 2003 American Heart Association Scientific Statement [12] and was categorized as either ST-elevation MI (STEMI) or non-STEMI. We included only patients who were classified as "definite" MI. We defined "acute reperfusion" as the administration of thrombolysis or PCI within 12 hours of the first symptom of MI. Preexisting cardiovascular risk factors and comorbidities were recorded if they were documented in the medical chart or if the patient was receiving treatment for the condition during the MI admission. The documentation of a medical condition in the chart was largely due to patient self-report; however, results of prior investigations (for example, angiography, surgical procedures) or prior hospital admissions or both were also taken into consideration. Medications that we considered indicative of a medical condition included lipid-lowering agents (for hypercholesterolemia) and oral hypoglycemic agents or insulin (for diabetes mellitus).

\section{Chart-review procedure}

The RA patients' charts were first reviewed for confirmation of the diagnoses of RA and MI, as defined earlier. If the diagnoses of RA and MI were not confirmed, 
the patient was excluded from the study. If the diagnoses of RA and MI were confirmed, the patient was included in the study, and a full review of the chart was performed, as described later. For each RA patient in the study, a non-RA control matched for age at time of MI ( \pm 1 year), gender, treating hospital, and year of MI $( \pm 1$ year) was selected from the de-identified list. The control patients' charts were reviewed for a diagnosis of $\mathrm{MI}$, as defined earlier. If the diagnosis of MI was not confirmed, the patient was excluded from the study, and another control was selected from the de-identified list. If the diagnosis of MI was confirmed, the patient was included in the study, and a full review of the chart was performed.

Chart abstraction and data collection were performed by a trained research assistant using a structured audit form. The accuracy of the chart abstraction was verified by independent audit of $5 \%$ of the charts by a second investigator (SV). The RA patients' charts were reviewed for RArelated characteristics, including ACR diagnostic criteria [11], disease duration, extraarticular disease, and DMARD treatment in the past and at the time of the MI admission. The charts of all patients (RA and non-RA) were reviewed for: confirmation of MI and type of MI, conventional cardiovascular risk factors and other comorbidities (including prior MI), medications taken at time of MI admission, administration and timing of reperfusion therapy (thrombolysis or PCI), and post-MI events such as in-hospital death and coronary artery bypass graft surgery. The clinical setting of the MI was classified into one of three categories: (a) "community based," the MI occurred outside a hospital with no acute medical illness immediately preceding it; (b) "after medical illness," the patient was already an inpatient for a medical illness and experienced the MI as a complication during that hospital admission; or (c) "after surgical event," the patient was already an inpatient and had undergone a surgical procedure and experienced the MI as a complication during that hospital admission. Urgent reperfusion is not necessarily indicated in all cases of MI; however, in the event of STEMI, early thrombolysis or PCI is considered the standard of care [13]. In those patients who experienced an STEMI and did not receive acute reperfusion, the reason for lack of acute reperfusion was determined from extensive review of the chart and was categorized as either (a) delayed diagnosis due to late presentation; (b) delayed diagnosis due to diagnostic uncertainty; (c) presence of a contraindication; or (d) unable to ascertain the reason. We also recorded whether treatment with secondary prevention medications (specifically aspirin, beta blockers, angiotensin-converting enzyme (ACE) inhibitors, lipid-lowering agents, or a combination of these) was commenced during the hospital stay for each patient. If a patient had an allergy or other condition precluding the use of these medications, or if the patient was previously taking the medication and it was continued during the MI admission, the treatment was considered to have been provided.

\section{Statistical analysis}

The primary end point was the proportion of patients who received acute reperfusion after MI. In performing our sample-size calculation, we used data from our previous study, in which we found that RA patients were treated with PCI half as often as non-RA patients. Assuming acute reperfusion rates of $50 \%$ in the control patients and $25 \%$ in the RA patients, with power $=0.9$ and alpha $=0.05$, we calculated that a sample of 85 participants per group would be required. Descriptive data were summarized by using population means and standard deviation or percentages, as appropriate. Baseline characteristics and treatment with secondary prevention medications of the RA and control patients were compared by using the McNemar test for categoric variables and the paired $t$ test for continuous variables. Treatment with cardiac interventions such as acute reperfusion, thrombolysis, and PCI in the RA and control patients was compared with the McNemar test (unadjusted analysis) and with conditional logistic regression adjusted for clinical setting of MI, type of MI, and prior MI. Our study covered a 10-year period during which the treatment of acute coronary syndromes evolved considerably. We therefore performed a post hoc analysis in which we compared treatment with acute reperfusion and secondary prevention pharmacotherapy between RA and controls over three time periods: prior to 1999, 1999 to 2002 inclusive, and after 2002. Analyses were performed with the use of Stata software version 10.0 (StataCorp, College Station, TX, USA).

\section{Results}

Demographic details, cardiovascular risk factors, and other comorbidities of the RA and control patients are shown (Table 1). Fifty-five (61\%) of the patients were women, with a mean age of $71 \pm 10$ years. The RA group had longstanding disease (mean disease duration, $20 \pm 13$ years) and were taking an average of 1.4 DMARDs at the time of the MI. Only one RA patient was using a biologic DMARD. Forty-nine (54\%) of the RA patients had sufficient documentation in the chart to confirm the diagnosis of RA according to ACR criteria. Seventy-eight (87\%) of the RA patients either fulfilled ACR criteria or were taking one or more DMARDs at the time of the MI.

No difference was found in the prevalence of traditional cardiovascular risk factors between the two groups, with the exception of hyperlipidemia, which was less prevalent in the RA group than in the control group ( $24 \%$ versus $42 \%$; $P=0.02)$. The prevalence of ischemic heart 
Table 1 Demographic and clinical features of the RA and control patients admitted to participating Victorian hospitals with acute MI between 1995 and 2005

\begin{tabular}{|c|c|c|}
\hline & RA $(n=90)$ & $\begin{array}{l}\text { Controls } \\
(n=90)\end{array}$ \\
\hline Female, $n(\%)$ & $55(61)$ & $55(61)$ \\
\hline Age in years, mean (SD) & $71(10)$ & $71(10)$ \\
\hline RA disease duration in years, mean (SD) & $20(13)$ & - \\
\hline Seropositive, $n(\%)^{a}$ & $35(78)$ & - \\
\hline No. of DMARDs, mean (SD) & $1.4(1.1)$ & - \\
\hline Taking NSAID at time of MI, $n(\%)$ & $21(23)$ & $6(7)^{b}$ \\
\hline \multicolumn{3}{|l|}{ Preexisting comorbidities: } \\
\hline Ischemic heart disease, $n(\%)$ & $31(34)$ & $33(37)$ \\
\hline Prior Ml, $n(\%)$ & $10(11)$ & $11(12)$ \\
\hline Cerebrovascular disease, $n(\%)$ & $8(9)$ & $9(10)$ \\
\hline Peripheral vascular disease, $n(\%)$ & $19(21)$ & $5(6)^{b}$ \\
\hline IDDM, $n(\%)$ & $3(3)$ & $1(1)$ \\
\hline NIDDM, $n(\%)$ & $22(24)$ & $27(30)$ \\
\hline Hypertension, $n(\%)$ & $52(58)$ & $56(62)$ \\
\hline Hypercholesterolemia, n (\%) & $22(24)$ & $38(42)^{b}$ \\
\hline Current smoker, $n(\%)$ & $14(15)$ & $16(18)$ \\
\hline Previous smoker, $n(\%)$ & $41(46)$ & $27(30)$ \\
\hline Congestive cardiac failure, $n(\%)$ & $15(17)$ & $11(12)$ \\
\hline Chronic lung disease, $n(\%)$ & $28(31)$ & $16(18)$ \\
\hline Chronic renal impairment, $n$ (\%) & $15(17)$ & $8(9)$ \\
\hline
\end{tabular}

Chronic lung disease: asthma, chronic obstructive airways disease, and pulmonary fibrosis; DMARD, disease-modifying antirheumatic drug; IDDM, insulin-dependent diabetes mellitus; MI, myocardial infarction; NIDDM, noninsulin-dependent diabetes mellitus; NSAID, nonsteroidal antiinflammatory drug; RA, rheumatoid arthritis. ${ }^{\mathrm{a}}$ Data available for 45 of 90 RA patients. ${ }^{b} P$ value $<0.05$

disease, prior MI, and cerebrovascular disease was similar in the two groups; however, peripheral vascular disease was more common in the RA group than in the control group (21\% versus $6 \% ; P=0.002)$.

\section{Reperfusion therapy}

Table 2 shows the treatment received by the RA and control patients after acute MI. No difference was noted between hospitals in the proportion of patients who received acute reperfusion (data not shown), so we present combined hospital data. In the unadjusted analysis, the RA patients were significantly less likely to receive acute reperfusion compared with the controls (16\% versus $37 \%$, respectively; OR, 0.27 ; $95 \%$ CI, 0.10 to 0.64 ). Thrombolysis was performed in 9\% of the RA patients compared with $24 \%$ of the controls (OR, 0.3 ; 95\% CI, 0.1 to 0.77 ); PCI was performed in $11 \%$ of the RA patients compared with $33 \%$ of the controls (OR, 0.2; 95\% CI, 0.06 to 0.53 ); and coronary angiography was performed in $43 \%$ of the RA patients compared with $58 \%$ of the controls (OR, $0.41 ; 95 \%$ CI, 0.16 to 0.92 ). Coronary artery bypass surgery was performed more frequently in the controls; however, this variance did not reach statistical significance.

The presence of a medical or surgical illness immediately before the MI was substantially more common in the RA patients than in the controls (31\% versus $16 \%$, respectively: OR, $2.5 ; 95 \% \mathrm{CI}, 1.2$ to 5.5 ). The clinical setting of the MI, the type of MI, and the past history of MI could potentially have affected the likelihood that acute reperfusion was provided. Therefore, we performed an analysis by using conditional logistic regression, with adjustment for these variables (Table 2). In the adjusted analysis, RA patients remained significantly less likely to be treated with acute reperfusion, thrombolysis, and PCI, suggesting that acute concurrent conditions or prior MI or both were not responsible for the observed differential treatment of RA patients.

We also performed an analysis restricted to the subgroup of RA patients who fulfilled ACR criteria $(n=49)$ along with their matched controls. Compared with the controls, the ACR-defined RA patients were significantly less likely to receive acute reperfusion (OR, 0.31; 95\% $\mathrm{CI}, 0.11$ to 0.85 ), thrombolysis (OR, $0.14 ; 95 \% \mathrm{CI}, 0.03$ to 0.62 ), and PCI (OR, 0.27; 95\% CI, 0.07 to 0.98 ). Coronary angiography and coronary artery bypass surgery were performed more frequently in the controls; however, this variance did not reach statistical significance.

Table 2 Treatment received by RA and control patients after myocardial infarction

\begin{tabular}{|c|c|c|c|c|c|c|c|c|}
\hline \multirow[b]{3}{*}{$\overline{\text { Acute reperfusion }^{c}}$} & \multicolumn{2}{|c|}{$\mathrm{RA}(n=90)$} & \multicolumn{2}{|c|}{ Controls $(n=90)$} & & & & \\
\hline & \multirow{2}{*}{$\begin{array}{c}n \\
14\end{array}$} & \multirow{2}{*}{$\begin{array}{c}\% \\
16\end{array}$} & \multirow{2}{*}{$\begin{array}{c}n \\
33\end{array}$} & \multirow{2}{*}{\begin{tabular}{|l|}
$\%$ \\
37
\end{tabular}} & \multicolumn{2}{|c|}{$\begin{array}{c}\text { Unadjusted OR } \\
(95 \% \mathrm{Cl})\end{array}$} & \multicolumn{2}{|c|}{$\begin{array}{c}\text { Adjusted OR } \\
(95 \% \mathrm{CI})\end{array}$} \\
\hline & & & & & 0.27 & $(0.10-0.64)$ & 0.21 & $(0.07-0.62)$ \\
\hline Thrombolysis & 8 & 9 & 22 & 24 & 0.30 & $(0.10-0.77)$ & 0.33 & $(0.11-0.96)$ \\
\hline $\mathrm{PCl}$ & 10 & 11 & 30 & 33 & 0.20 & $(0.06-0.53)$ & 0.23 & $(0.09-0.63)$ \\
\hline PCA & 39 & 43 & 52 & 58 & 0.41 & $(0.16-0.92)$ & 0.54 & $(0.23-1.25)$ \\
\hline CABGS & 11 & 12 & 17 & 19 & 0.57 & $(0.21-1.46)$ & 0.67 & $(0.27-1.65)$ \\
\hline
\end{tabular}

CABGS, coronary artery bypass graft surgery; $\mathrm{Cl}$, confidence interval; OR, odds ratio; $\mathrm{PCA}$, percutaneous coronary angiography; $\mathrm{PCl}$, percutaneous coronary intervention (angioplasty \pm insertion of stent); RA, rheumatoid arthritis. ${ }^{\mathrm{a}} \mathrm{McNemar} \chi^{2}$ test. ${ }^{\mathrm{b}}$ Conditional logistic regression, adjusting for type of MI (STEMI or NSTEMI), presence of prior $\mathrm{Ml}$, and clinical setting of $\mathrm{MI}$. 'Acute reperfusion defined as the administration of thrombolysis or PCl within 12 hours of the first symptom of MI. 


\section{Characteristics of patients not receiving reperfusion therapy}

From our total study cohort of 180 patients, 29 of the RA patients and 39 of the controls were diagnosed with STEMI. Acute reperfusion was administered in $48 \%$ of the RA-STEMI patients versus $74 \%$ of the control-STEMI patients $\left(P=0.027\right.$ with the $\chi^{2}$ test $)$. In those STEMI patients who did not receive acute reperfusion $(n=25)$, delayed diagnosis of MI was the most common reason for failure to provide acute reperfusion: six (40\%) of RA patients and five (50\%) of controls. It was previously demonstrated that RA patients experience a higher rate of silent MI than does the general population, and this may also contribute to a delay in presentation to hospital $[9,14]$. In our study, $39 \%$ of the RA patients did not experience chest pain during the MI compared with $22 \%$ of the control patients (OR, 0.5 ; $95 \% \mathrm{CI}, 0.3$ to 0.9 ). A contraindication to acute reperfusion was present in five (33\%) of the RA patients, whereas none of the controls had a contraindication. In four (27\%) of the RA patients and five (50\%) of the controls, no clear reason was found for not providing acute reperfusion after careful review of the medical chart.

The numbers were too small in this subgroup of 25 patients to make any meaningful statistical comparisons; however, the difference in the prevalence of contraindication to acute reperfusion between the RA and control groups was of interest. Five RA patients had a contraindication to acute reperfusion; one had peptic ulcer disease (bleeding risk), one had a recent intracerebral bleed, and three patients had undergone major surgery in the previous 5 days. This was consistent with our finding that an antecedent medical illness or surgical event was more common in the RA subjects.

\section{Secondary prevention therapy}

Table 3 shows the number of RA and control patients who received treatment with selected secondary prevention medications. The RA patients received less-frequent treatment with beta blockers (71\% versus $83 \%$ : OR, 0.42 (95\% CI, 0.18 to 0.96$)$ ) and lipid-lowering agents (40\% versus $70 \%$ : OR, 0.21 (95\% CI, 0.09 to 0.46$)$ ).

Ten of the RA patients and 11 of the controls had experienced MI before the study "MI admission." Table 4 shows the numbers of these patients who were already taking selected secondary prevention medications at the time of the study MI. The RA patients had lower rates of treatment with aspirin, beta blockers, and lipid-lowering agents at the time of their recurrent MI. These data mirror our findings in the analysis of the entire cohort and serve to validate the results of the present study.

\section{Changes in post-MI care over time}

Table 5 shows the frequency of selected post-MI treatments in RA and control patients for three time periods
Table 3 In-hospital treatment with secondary prevention medications received by $\mathrm{RA}$ and control patients after myocardial infarction

\begin{tabular}{|c|c|c|c|c|c|c|}
\hline \multirow[b]{3}{*}{ Aspirin } & \multicolumn{2}{|c|}{$\begin{array}{c}\text { RA } \\
(n=90)\end{array}$} & \multicolumn{2}{|c|}{$\begin{array}{l}\text { Controls } \\
(n=90)\end{array}$} & & \\
\hline & \multirow{2}{*}{$\begin{array}{c}\boldsymbol{n} \\
85\end{array}$} & \multirow{2}{*}{$\begin{array}{l}\% \\
94\end{array}$} & \multirow{2}{*}{$\begin{array}{c}\boldsymbol{n} \\
89\end{array}$} & \multirow{2}{*}{$\begin{array}{l}\% \\
99\end{array}$} & \multicolumn{2}{|c|}{$\mathrm{OR}^{\mathrm{a}}(95 \% \mathrm{Cl})$} \\
\hline & & & & & 0.20 & $(0.02-1.71)$ \\
\hline Beta blockers & 64 & 71 & 75 & 83 & 0.42 & $(0.18-0.96)$ \\
\hline ACE inhibitors & 61 & 68 & 57 & 63 & 1.18 & $(0.67-2.08)$ \\
\hline Lipid-lowering agents & 36 & 40 & 63 & 70 & 0.21 & $(0.09-0.46)$ \\
\hline
\end{tabular}

$\mathrm{ACE}$, angiotensin-converting enzyme; $\mathrm{Cl}$, confidence interval; $\mathrm{OR}$, odds ratio; $\mathrm{RA}$, rheumatoid arthritis. ${ }^{\mathrm{a}} \mathrm{McNemar} \chi^{2}$ test. Acute reperfusion is defined as the administration of thrombolysis or $\mathrm{PCl}$ within 12 hours of the first symptom of MI.

within our study period: prior to 1999, 1999 through 2002, inclusive, and 2003 and onward. For virtually all interventions, in each of the time periods, the RA patients received less-frequent treatment than did the controls. Within the subgroup of STEMI patients, a suggestion of higher rates of acute reperfusion was found in the most recent time period (small numbers limit this result); however, in all time periods, the RA patients received less-frequent acute reperfusion than did the controls. Treatment with lipid-lowering agents increased progressively over time for all patients; however, in each time period, RA patients again received less-frequent treatment with lipid-lowering agents than did controls.

\section{Discussion}

We previously demonstrated an almost twofold increase in the 30-day case-fatality rate after MI in RA patients; however, the reason(s) for this increased mortality were not clear. In the present study, we investigated whether this difference in case fatality might be partially explained by RA patients receiving different rates of treatment with acute reperfusion or secondary prevention medications or both after the acute event.

We found that RA patients were substantially less likely to be treated with acute reperfusion after MI, and that this difference persisted after adjusting for type of $\mathrm{MI}$, clinical setting of the MI, and prior MI (OR, 0.2; $95 \% \mathrm{CI}, 0.05$ to 0.6 ). We attempted to determine the explanation for this discrepancy by examining the charts

Table 4 Use of secondary prevention medications at the time of "MI admission" in RA and control patients with a prior history of MI

\begin{tabular}{lcc}
\hline & RA $(\boldsymbol{n}=\mathbf{1 0})$ & Controls $(\boldsymbol{n}=\mathbf{1 1})$ \\
\hline Aspirin, $n(\%)$ & $3(30)$ & $6(55)$ \\
Beta blocker, $n(\%)$ & $1(10)$ & $4(36)$ \\
ACE inhibitor, $n(\%)$ & $3(30)$ & $3(27)$ \\
Lipid-lowering agent, $n(\%)$ & $2(20)$ & $5(45)$ \\
\hline
\end{tabular}

$\mathrm{ACE}$, angiotensin-converting enzyme; $\mathrm{RA}$, rheumatoid arthritis. 
Table 5 Post-MI treatment in RA and control patients: comparison of three time periods

\begin{tabular}{|c|c|c|c|}
\hline & Prior to 1999 & 1999 to 2002 inclusive & 2003 onward \\
\hline \multicolumn{4}{|c|}{ Acute reperfusion (all patients) } \\
\hline RA patients, $n(\%)$ & $6 / 16(38 \%)$ & $4 / 38(10 \%)^{*}$ & $4 / 28(12 \%)$ \\
\hline Controls, $n(\%)$ & $10 / 19(53 \%)$ & $17 / 41(41 \%)$ & $6 / 30(20 \%)$ \\
\hline \multicolumn{4}{|c|}{ Acute reperfusion (STEMI patients) } \\
\hline RA patients, $n(\%)$ & $6 / 10(60 \%)$ & $4 / 13(31 \%)^{*}$ & $4 / 6(67 \%)$ \\
\hline Controls, $n(\%)$ & $9 / 12(75 \%)$ & $14 / 20(70 \%)$ & $6 / 7(86 \%)$ \\
\hline \multicolumn{4}{|l|}{ Thrombolysis } \\
\hline RA patients, $n(\%)$ & $3 / 16(19 \%)$ & $3 / 42(7 \%)^{*}$ & $2 / 32(6 \%)$ \\
\hline Controls, $n(\%)$ & $8 / 19(42 \%)$ & $12 / 41(29 \%)$ & $2 / 30(7 \%)$ \\
\hline \multicolumn{4}{|c|}{ Percutaneous coronary intervention } \\
\hline RA patients, $n(\%)$ & $4 / 16(25 \%)$ & $3 / 42(7 \%)^{*}$ & $3 / 32(9 \%)^{*}$ \\
\hline Controls, $n(\%)$ & $3 / 19(16 \%)$ & 15/41 (36\%) & $12 / 30(40 \%)$ \\
\hline \multicolumn{4}{|l|}{ Aspirin } \\
\hline RA patients, $n(\%)$ & 14/16 (88\%) & $41 / 42(98 \%)$ & $30 / 32(94 \%)$ \\
\hline Controls, $n(\%)$ & 19/19 (100\%) & $41 / 41(100 \%)$ & 29/30 (97\%) \\
\hline \multicolumn{4}{|l|}{ Beta blockers } \\
\hline RA patients, $n(\%)$ & $8 / 16(50 \%)$ & $32 / 42(76 \%)$ & $24 / 32(75 \%)$ \\
\hline Controls, $n(\%)$ & 15/19 (79\%) & $32 / 41(78 \%)$ & 28/30 (93\%) \\
\hline \multicolumn{4}{|l|}{ ACE inhibitors } \\
\hline RA patients, $n(\%)$ & $8 / 16(50 \%)$ & 29/42 (69\%) & 24/32 (75\%) \\
\hline Controls, $n(\%)$ & 14/19 (74\%) & 24/41 (58\%) & 19/30 (63\%) \\
\hline \multicolumn{4}{|l|}{ Lipid-lowering agents } \\
\hline RA patients, $n(\%)$ & $0 / 16(0)^{*}$ & $16 / 42(38 \%)^{*}$ & 20/32 (62\%) \\
\hline Controls, n (\%) & $7 / 19$ (37\%) & $31 / 41$ (76\%) & 25/30 (83\%) \\
\hline
\end{tabular}

ACE, angiotensin-converting enzyme; MI, myocardial infarction; RA, rheumatoid arthritis; STEMI, ST-elevation myocardial infarction. ${ }^{*} P<0.05$ for the comparison with control patients.

for the reasons for failure to provide acute reperfusion in STEMI patients. Diagnostic delay was the reason for failure to treat in 11 (44\%) of the 25 STEMI patients who did not receive acute reperfusion. Delayed presentation was more common in the RA patients, whereas a delay in confirming the diagnosis (after presentation) was more common in the controls. No identifiable reason was found for failure to treat in nine $(36 \%)$ of the 25 STEMI patients who did not receive acute reperfusion.

Within the group of STEMI patients who did not receive acute reperfusion, the most obvious difference between the RA and control patients was in the frequency of contraindication to acute reperfusion. In one third of the RA STEMI patients who did not receive acute reperfusion, the reason recorded was the presence of a contraindication-in most cases, a preceding acute medical or surgical event. Similarly, in the overall cohort of 180 patients, a preceding medical illness or surgical event was more common in the RA patients than in the controls (31\% versus 16\%, respectively). Lichtman et al. [15] demonstrated in non-RA patients that the presence of a concurrent acute, severe, noncardiac condition at the time of MI was associated with lower rates of treatment with reperfusion therapy (even among patients who were "ideal candidates") and was associated with higher in-hospital mortality. Although the higher rate of concomitant illness in the RA patients in our study may have contributed to lower rates of acute reperfusion and secondary prevention therapy in this group, it is important to emphasize that the discrepancies persisted even with analysis adjusted for the clinical setting of MI.

Secondary prevention with medications such as aspirin, beta blockers, angiotensin-converting enzyme (ACE) inhibitors, and lipid-lowering agents is an important component of post-MI care [13]. A major finding of our study was that RA patients received lower rates of treatment with secondary prevention medications after MI. This was evident both in the total study cohort and in those patients who had experienced MI before the "MI admission." In the decade covered by our study, RA patients were $58 \%$ less likely to receive treatment with beta blockers and $79 \%$ less likely to receive treatment with lipid-lowering agents. Given that prompt implementation of reperfusion therapy and post-MI treatment with beta blockers and lipid-lowering agents are major determinants of outcome after acute MI, this lower rate of treatment after MI may help to explain why case-fatality rates are higher in RA than in the general population. It is unclear why RA patients were 
undertreated with secondary prevention medications; the discrepancy is not explained by differences in the prevalence of contraindication or serious comorbidity, because in these instances, the treatment was considered to have been provided. It is possible that concerns regarding toxicity, such as myositis, or exacerbating polypharmacy in the RA patients led to reluctance to prescribe additional medications.

Our study covered a 10-year period from 1995 to 2005 , during which time the treatment of acute coronary syndromes evolved considerably. In the late 1990s and early 2000 s, a significant shift occurred toward more-aggressive use of reperfusion therapy and routine prescription of lipid-lowering agents for secondary prevention of acute coronary syndromes (regardless of lipid levels) after publication of evidence supporting this practice [16-19]. Our study design, in which patients are matched for year of MI, compensates for changing practice over time. Having demonstrated lower rates of acute reperfusion and secondary prevention treatment in the RA patients, we were interested to explore the pattern of treatment over time. We found that for virtually all interventions, the RA patients received lessfrequent treatment than did the controls, and that the differences persisted throughout all time periods. This suggests that the relative undertreatment of RA patients who experience $\mathrm{MI}$ is ongoing, despite the considerable literature relating to cardiovascular risk in RA.

This study has a number of potential limitations. We sampled only a small proportion of the RA patients in Victoria who experienced a hospital admission for MI over the 10-year study period. During the case-selection process, RA patients could have been missed if they were not coded as having RA during their hospital admission(s). The Victorian hospital coding standard requires that concurrent diagnoses that receive treatment during hospitalization be coded. Between 12 and 40 concurrent diagnoses are coded, depending on the year. It would therefore be expected that an RA patient whose medications were continued in hospital during the MI admission would be coded as RA, regardless of whether they had ever been admitted for RA. Misclassification would be more likely for patients with mild RA (not receiving any treatment) and may mean that only RA patients with more-severe disease were included in the study. Increased ascertainment of RA status in patients who experienced MI in the context of a rheumatoid-related admission is also possible. Such misclassification could mean that our sample is not representative of the full spectrum of RA patients and that our results may be relevant only to patients with more-severe disease. Our study included only metropolitan hospitals, so may not reflect practice in rural locations. Diagnosis of cardiovascular risk factors and other comorbidities was based on patient self-report and therefore may be inaccurate; however, the degree of inaccuracy is unlikely to be different between the RA and control groups. Furthermore, the presence or absence of the listed cardiovascular risk factors and comorbidities are not determinants of whether to provide acute reperfusion in the event of MI and thus do not act as confounders in the comparison. In one third of STEMI patients, no reason was ascertainable for not providing acute reperfusion treatment. It is possible that valid reasons existed for some or all of these episodes of "failure to treat," but that this rationale was not documented and therefore not apparent to the investigators. Again, it is unlikely that documentation omissions were distributed differently between RA and non-RA cases; therefore, bias is unlikely.

\section{Conclusions}

In this retrospective study of 90 RA patients and 90 matched controls with acute MI, we found that the RA group received acute reperfusion and secondary prevention medications less frequently than did the control group. These discrepancies persisted despite adjustment for relevant clinical factors and were present within all time periods within the study duration. RA patients should be considered a high-risk group after MI and considered for acute reperfusion therapy along the same lines as the general population, in line with current best practice. In the absence of contraindications, RA patients should also receive recommended secondary prevention therapy after MI, in keeping with evidencebased guidelines for the general population.

\section{Abbreviations}

ACE: angiotensin converting enzyme; ACR: American College of Rheumatology; CABGS: coronary artery bypass graft surgery; Cl: confidence interval; DMARD: disease modifying anti-rheumatic drug; ICD: International Classification of Diseases; IDDM: insulin dependent diabetes mellitus; MI: myocardial infarction; NIDDM: non-insulin-dependent diabetes mellitus; NSAID: nonsteroidal anti-inflammatory drug; OR: odds ratio; PCA: percutaneous coronary angiography; $\mathrm{PCl}$ : percutaneous intervention; RA: rheumatoid arthritis; STEMI: ST-elevation myocardial infarction.

\section{Acknowledgements}

We gratefully acknowledge the assistance of Ms Angela Wood in the chart abstraction and Ms Alexandra Gorelik for statistical advice. This research was supported by an Arthritis Australia Grant-in-aid (Win Dunne Grant) and The Walkom Trust. The funding bodies had no role in the study design, completion, or writing of the manuscript. IPW is supported by a Clinical Practitioner Fellowship (461203) from the National Health and Medical Research Council of Australia.

\section{Author details}

'Department of Medicine (RMH/WH), The University of Melbourne, Grattan Street, Parkville, 3050, Australia. ²Department of Rheumatology, Royal Melbourne Hospital, Grattan Street, Parkville, 3050, Australia. ${ }^{3}$ Clinical Epidemiology \& Health Services Evaluation Unit, Royal Melbourne Hospital, Grattan Street, Parkville, 3050, Australia. ${ }^{4}$ Centre for Research Excellence in Patient Safety, Monash University, Commercial Road, Melbourne, 3004, Australia. ${ }^{5}$ Department of Medicine (Southern Clinical School), Monash 
University, Clayton Road, Clayton, 3168, Australia. ${ }^{6}$ Department of Cardiology, Royal Melbourne Hospital, Grattan Street, Parkville, 3050, Australia. ${ }^{7}$ NHMRC Centre of Clinical Research Excellence in Therapeutics, Department of Epidemiology and Preventive Medicine, Monash University, Commercial Road, Melbourne, 3004, Australia.

\section{Authors' contributions}

SV conceived the study, coordinated the design and completion, supervised the chart-review process, performed the statistical analysis, and drafted the manuscript. CB and VS assisted in the design of the study and statistical analysis and helped to draft the manuscript. AA and IW assisted in the design of the study and helped to draft the manuscript. All authors read and approved the final manuscript.

\section{Competing interests}

The authors declare that they have no competing interests.

Received: 17 June 2010 Revised: 2 September 2010

Accepted: 7 October 2010 Published: 7 October 2010

\section{References}

1. Van Doornum S, McColl G, Wicks IP: Accelerated atherosclerosis: an extraarticular feature of rheumatoid arthritis? Arthritis Rheum 2002, 46:862-873.

2. Australian Institute of Health and Welfare 2008: Arthritis and Osteoporosis in Australia 2008. Arthritis series Canberra: AlHW, 8, Cat. no. PHE 106.

3. Solomon DH, Karlson EW, Rimm EB, Cannuscio CC, Mandl LA, Manson JE, Stampfer MJ, Curhan GC: Cardiovascular morbidity and mortality in women diagnosed with rheumatoid arthritis. Circulation 2003, 107:1303-1307.

4. Wallberg-Jonsson S, Ohman ML, Dahlqvist SR: Cardiovascular morbidity and mortality in patients with seropositive rheumatoid arthritis in northern Sweden. J Rheumatol 1997, 24:445-451.

5. Wolfe F, Mitchell DM, Sibley JT, Fries JF, Bloch DA, Williams CA, Spitz PW, Haga M, Kleinheksel SM, Cathey MA: The mortality of rheumatoid arthritis. Arthritis Rheum 1994, 37:481-494.

6. Goodson N, Marks J, Lunt M, Symmons D: Cardiovascular admissions and mortality in an inception cohort of patients with rheumatoid arthritis with onset in the 1980s and 1990s. Ann Rheum Dis 2005, 64:1595-1601.

7. Solomon DH, Goodson NJ, Katz JN, Weinblatt ME, Avorn J, Setoguchi S, Canning C, Schneeweiss S: Patterns of cardiovascular risk in rheumatoid arthritis. Ann Rheum Dis 2006, 65:1608-1612.

8. Van Doornum S, Brand C, King B, Sundararajan V: Increased case fatality rates following a first acute cardiovascular event in patients with rheumatoid arthritis. Arthritis Rheum 2006, 54:2061-2068.

9. Douglas KM, Pace AV, Treharne GJ, Saratzis A, Nightingale P, Erb N, Banks MJ, Kitas GD: Excess recurrent cardiac events in rheumatoid arthritis patients with acute coronary syndrome. Ann Rheum Dis 2006, 65:348-353.

10. Sodergren A, Stegmayr B, Lundberg V, Ohman ML, Wallberg-Jonsson S: Increased incidence of and impaired prognosis after acute myocardial infarction among patients with seropositive rheumatoid arthritis. Ann Rheum Dis 2007, 66:263-266.

11. Arnett FC, Edworthy SM, Bloch DA, McShane DJ, Fries JF, Cooper NS, Healey LA, Kaplan SR, Liang MH, Luthra HS, Medsger TA, Mitchell DM, Neustadt DH, Pinals RS, Schaller JG, Sharp JT, Wilder RL, Hunder GG: The American Rheumatism Association 1987 revised criteria for the classification of rheumatoid arthritis. Arthritis Rheum 1988, 31:315-324.

12. Luepker RV, Apple FS, Christenson RH, Crow RS, Fortmann SP, Goff D, Goldberg RJ, Hand MM, Jaffe AS, Julian DG, Levy D, Manolio T, Mendis S, Mensah G, Pajak A, Prineas RJ, Reddy KS, Roger VL, Rosamond WD, Shahar E, Sharrett AR, Sorlie P, Tunstall-Pedoe H: Case definitions for acute coronary heart disease in epidemiology and clinical research studies: a statement from the AHA Council on Epidemiology and Prevention; AHA Statistics Committee; World Heart Federation Council on Epidemiology and Prevention; the European Society of Cardiology Working Group on Epidemiology and Prevention; Centers for Disease Control and Prevention; and the National Heart, Lung, and Blood Institute. Circulation 2003, 108:2543-2549.

13. Antman EM, Anbe DT, Armstrong PW, Bates ER, Green LA, Hand M, Hochman JS, Krumholz HM, Kushner FG, Lamas GA, Mullany CJ, Ornato JP,
Pearle DL, Sloan MA, Smith SC Jr, Alpert JS, Anderson JL, Faxon DP, Fuster V, Gibbons RJ, Gregoratos G, Halperin JL, Hiratzka LF, Hunt SA, Jacobs AK: ACC/AHA guidelines for the management of patients with STelevation myocardial infarction: a report of the American College of Cardiology/American Heart Association Task Force on Practice Guidelines (Committee to Revise the 1999 Guidelines for the Management of Patients with Acute Myocardial Infarction). Circulation 2004, 110:e82-e292.

14. Maradit-Kremers H, Crowson CS, Nicola PJ, Ballman KV, Roger VL, Jacobsen SJ, Gabriel SE: Increased unrecognized coronary heart disease and sudden deaths in rheumatoid arthritis: a population-based cohort study. Arthritis Rheum 2005, 52:402-411.

15. Lichtman JH, Spertus JA, Reid KJ, Radford MJ, Rumsfeld JS, Allen NB, Masoudi FA, Weintraub WS, Krumholz HM: Acute noncardiac conditions and in-hospital mortality in patients with acute myocardial infarction. Circulation 2007, 116:1925-1930.

16. Scandinavian Simvastatin Survival Study: Randomised trial of cholesterol lowering in 4444 patients with coronary heart disease: the Scandinavian Simvastatin Survival Study (4S). Lancet 1994, 344:1383-1389.

17. Sacks FM, Pfeffer MA, Moye LA, Rouleau JL, Rutherford JD, Cole TG, Brown L, Warnica JW, Arnold JM, Wun CC, Davis BR, Braunwald E: The effect of pravastatin on coronary events after myocardial infarction in patients with average cholesterol levels: Cholesterol and Recurrent Events Trial investigators. N Engl J Med 1996, 335:1001-1009.

18. Long-Term Intervention with Pravastatin in Ischaemic Disease (LIPID) Study Group: Prevention of cardiovascular events and death with pravastatin in patients with coronary heart disease and a broad range of initial cholesterol levels: the Long-Term Intervention with Pravastatin in Ischaemic Disease (LIPID) Study Group. N Engl J Med 1998, 339:1349-1357.

19. Schwartz GG, Olsson AG, Ezekowitz MD, Ganz P, Oliver MF, Waters D, Zeiher A, Chaitman BR, Leslie S, Stern T: Effects of atorvastatin on early recurrent ischemic events in acute coronary syndromes: the MIRACL study: a randomized controlled trial. JAMA 2001, 285:1711-1718.

doi:10.1186/ar3151

Cite this article as: Van Doornum et al: Rheumatoid arthritis patients receive less frequent acute reperfusion and secondary prevention therapy after myocardial infarction compared with the general population. Arthritis Research \& Therapy 2010 12:R183.

\section{Submit your next manuscript to BioMed Central and take full advantage of:}

- Convenient online submission

- Thorough peer review

- No space constraints or color figure charges

- Immediate publication on acceptance

- Inclusion in PubMed, CAS, Scopus and Google Scholar

- Research which is freely available for redistribution 